\title{
Perioperative outcomes of robotic surgery for the treatment of lung cancer compared to a conventional video-assisted thoracoscopic surgery (VATS) technique
}

\author{
Zipu Yu ${ }^{1, *}$, Qiong Xie ${ }^{2,}{ }^{*}$, Lei Guo ${ }^{2}$, Xin Chen ${ }^{2}$, Chenyao $\mathrm{Ni}^{2}$, Wenzong Luo ${ }^{2}$, Weidong $\mathrm{Li}^{2}$ \\ and Liang $\mathrm{Ma}^{2}$ \\ ${ }^{1}$ Department of Thoracic Surgery, 2nd Affiliated Hospital, Zhejiang University, Hangzhou, China \\ ${ }^{2}$ Department of Cardiothoracic Surgery, 1st Affiliated Hospital, Zhejiang University, Hangzhou, China \\ *These authors contributed equally to this work \\ Correspondence to: Liang Ma, email: yuzipuleaf@sina.com \\ Weidong Li, email: 7714996@qq.com \\ Keywords: robotic, video-assisted thoracoscopic surgery, lung cancer, da Vinci robotic system, meta-analysis
}

Received: January 16, $2016 \quad$ Accepted: July 11, $2017 \quad$ Published: July 25, 2017

Copyright: Yu et al. This is an open-access article distributed under the terms of the Creative Commons Attribution License 3.0 (CC BY 3.0 ), which permits unrestricted use, distribution, and reproduction in any medium, provided the original author and source are credited.

\section{ABSTRACT}

Aim: To conduct a meta-analysis to determine the relative merits between robotic video-assisted thoracoscopic surgery (R-VATS) and conventional video-assisted thoracoscopic surgery (VATS) for lung cancer.

Results: Fifteen studies matched the selection criterion, which reported 8827 subjects, of whom 1704 underwent R-VATS and 7123 underwent VATS. Compared the perioperative outcomes with VATS, reports of R-VATS indicated unfavorable outcomes considering the operative time (SMD $=0.48,95 \% \mathrm{CI} 0.15$ to 0.81 ). Meanwhile, the number of dissected lymph nodes (SMD $=0.12,95 \% \mathrm{CI}-0.27$ to 0.51 ) and hospital stay following surgery (SMD $=-0.1 ; 95 \% \mathrm{CI}-0.27$ to 0.07 ), conversion $(\mathrm{RR}=0.68$; $95 \%$ CI 0.42 to 1.11 ), morbidity ( $R R=0.99,95 \%$ CI 0.92 to 1.07 ) and mortality ( $R R=0.33,95 \%$ CI 0.1 to 1.09$)$ were similar for both procedures.

Materials and Methods: A literature search was performed to identify comparative studies reporting perioperative outcomes for R-VATS and VATS for lung cancer. Pooled risk ratio (RR) and standardized mean differences (SMDs) with $95 \%$ confidence intervals ( $95 \%$ CIs) were calculated using either the fixed effects model or the random effects model.

Conclusions: There is no difference in terms of perioperative outcomes between R-VATS and VATS except for the operative time which is significantly high for R-VATS. Further studies are required to confirm these results.

\section{INTRODUCTION}

The introduction of minimally invasive surgery (MIS) has opened new possibilities in various surgical fields. Benefits of video-assisted thoracic surgery (VATS) have been reported for its shorter length of hospital stay, decreased pain, a more rapid return to normal activity [1-3]. Video-assisted thoracoscopic surgery (VATS) is widely accepted as a safe and useful approach for the management of various thoracic conditions [4]. However,
VATS still remains a technically challenging procedure owing to its two-dimensional visual representation and use of nonflexible endoscopic instruments.

Robotic surgery was introduced as an evolution of video-assisted thoracic surgery while maintaining advantages in part to overcome the limitations of VATS at the end of 1990s. The robotic approach has many advantages, which include greater flexibility and higher definition threedimensional vision, more intuitive movements and comfort of the surgeon via the use of wrist instruments $[5,6]$. 
Probably the first series using a robotic system to perform lung lobectomy was published in 2002 [7]. As a whole, robotic surgery still remains in its infancy.

Systematic review and meta-analysis is an important tool for revealing trends that might not be apparent in a single study. Pooling of independent but similar studies increases precision and confidence [8]. In this study, we aimed to determine the relative merits of R-VATS and VATS for lung cancer.

\section{RESULTS}

\section{Description of the included studies}

The initial search strategy retrieved 280 publications after removing duplications. Overall, 15 studies [9-23] met our entry criteria and were included in the analysis. A flow diagram of the study selection process is presented in Figure 1. All characteristics of studies are summarized in Table 1.

\section{Meta-analysis of intra-operative data}

The random-effects meta-analysis results indicated that the operating time was significantly different between R- VATS and VATS (SMD, 0.48; 95\% CI, 0.15-0.81; $P=0.005)$. The ten sets of results showed a significant amount of heterogeneity $\left(I^{2}=93 \%, P<0.00001\right)$ (Figure 2 ).

Seven studies reported on conversion. Conversion is adopted for the reason that it is difficult to perform operations as planned for R-VATS. Conversion of R-VATS is carried out by the way of using a rib-spreading thoracotomy or switching from robotic to conventional VATS. There was no significant difference between two groups $(\mathrm{RR}=0.68 ; 95 \% \mathrm{CI} 0.42$ to $1.11 ; P=0.13)$. There was no significant heterogeneity between the studies $\left(I^{2}=0 \%\right)$ (Figure 3).

\section{Meta-analysis of pathologic details}

In the five studies, there was no significant difference between two groups in the number of lymph nodes harvested $(\mathrm{SMD}=0.12,95 \% \mathrm{CI}-0.27$ to 0.51 ). The random-effects model was used because of the heterogeneity between the studies $\left(I^{2}=78 \%\right)$ (Figure 4$)$.

\section{Meta-analysis of post-operative outcomes}

In eight studies, length of hospital stay was found to be no significantly different between the R- VATS and VATS group. Meanwhile, analysis of the pooled data revealed that the two groups did not differ significantly in this regard (SMD: $-0.10 ; 95 \% \mathrm{CI}$ : -0.27 to $0.07 ; P=0.26$ ) (Figure 5).

In all fourteen studies, morbidity was found to be no significantly different between the R-VATS and VATS group. Meanwhile, analysis of the pooled data indicated that the two groups did not differ significantly in this regard $(\mathrm{RR}=0.99,95 \%$ CI 0.92 to $1.07 ; P=0.80)$ (Figure 6).

In nine studies, mortality was found to be no significantly different between the R- VATS and VATS group. Meanwhile, analysis of the pooled data demonstrated that the two groups did not differ significantly in this regard (RR: $0.33,95 \% \mathrm{CI}: 0.10$ to $1.09 ; P=0.07$ ) (Figure 7).

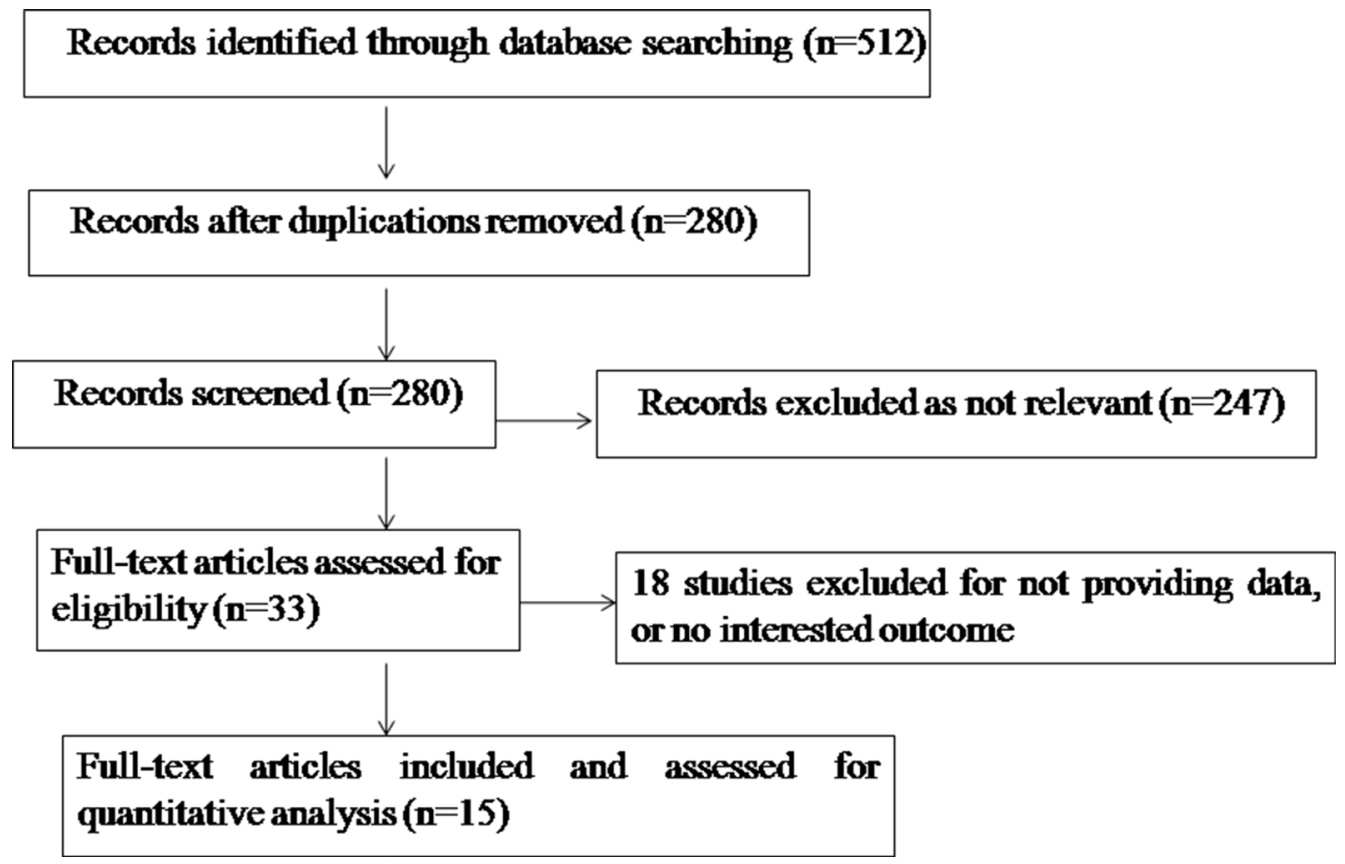

Figure 1: Flow chart indicating the process of selecting articles for meta-analysis. 
Table 1: Characteristics of included studies

\begin{tabular}{|c|c|c|c|c|c|c|c|}
\hline Study & Author & Year & Country & Design & Study quality & Group & $\begin{array}{c}\text { Patients in each } \\
\text { group, } n\end{array}$ \\
\hline 1 & R.Douglas Adams et al. & 2014 & USA & ROS & $4 / 9$ & R-VATS/ VATS & $116 / 4612$ \\
\hline 2 & Yong $\mathrm{He}$ et al. & 2014 & UK & POS & $7 / 9$ & R-VATS/ VATS & $30 / 34$ \\
\hline 3 & Julien Mahieu et al. & 2015 & France & ROS & $5 / 9$ & R-VATS/ VATS & $28 / 28$ \\
\hline 4 & Benjamin E. Lee et al. & 2015 & USA & ROS & $5 / 9$ & R-VATS/ VATS & $53 / 158$ \\
\hline 5 & Hyun-Sung Lee et al. & 2012 & Korea & ROS & $5 / 9$ & R-VATS/ VATS & $100 / 100$ \\
\hline 6 & Michael Kent et al. & 2014 & USA & ROS & $6 / 9$ & R-VATS/ VATS & $411 / 1233$ \\
\hline 7 & Florian Augustin et al. & 2013 & Austria & ROS & $7 / 9$ & R-VATS/ VATS & $26 / 26$ \\
\hline 8 & Brian E. Louie et al. & 2012 & USA & ROS & $6 / 9$ & R-VATS/ VATS & $46 / 34$ \\
\hline 9 & Scott J. Swanson et al. & 2014 & USA & ROS & $6 / 9$ & R-VATS/ VATS & $295+325 / 295+325$ \\
\hline 10 & Hee-Jin Jang et al. & 2011 & Korea & ROS & $6 / 9$ & R-VATS/ VATS & $40 / 40$ \\
\hline 11 & Shaun A. Deen et al. & 2014 & USA & ROS & $5 / 9$ & R-VATS/ VATS & $57 / 58$ \\
\hline 12 & Adalet Demir et al. & 2015 & Turkey & ROS & $6 / 9$ & R-VATS/ VATS & $34 / 65$ \\
\hline 13 & Benjamin E. Lee et al. & 2014 & USA & ROS & $7 / 9$ & R-VATS/ VATS & $35 / 34$ \\
\hline 14 & Benedetto Mungo et al. & 2016 & USA & ROS & $5 / 9$ & R-VATS/ VATS & $80 / 53$ \\
\hline 15 & Julien Mahieu et al. & 2016 & France & ROS & $4 / 9$ & R-VATS/ VATS & $28 / 28$ \\
\hline
\end{tabular}

ROS: retrospective observational study; POS: prospective observational study; VATS: video-assisted thoracoscopic surgery; R-VATS: robotic video-assisted thoracoscopic surgery.



Figure 2: Forest plot presenting operating time from the studies included. $95 \%$ CI: $95 \%$ confidence interval.

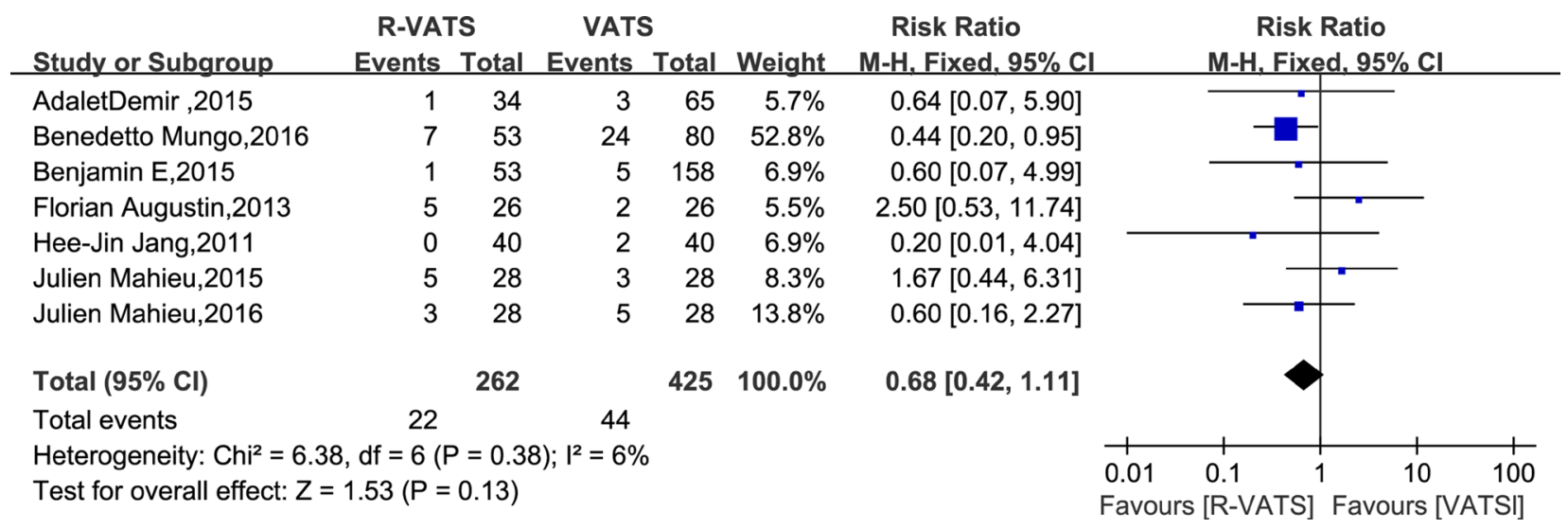

Figure 3: Forest plot presenting conversion from the studies included. $95 \%$ CI: $95 \%$ confidence interval. 


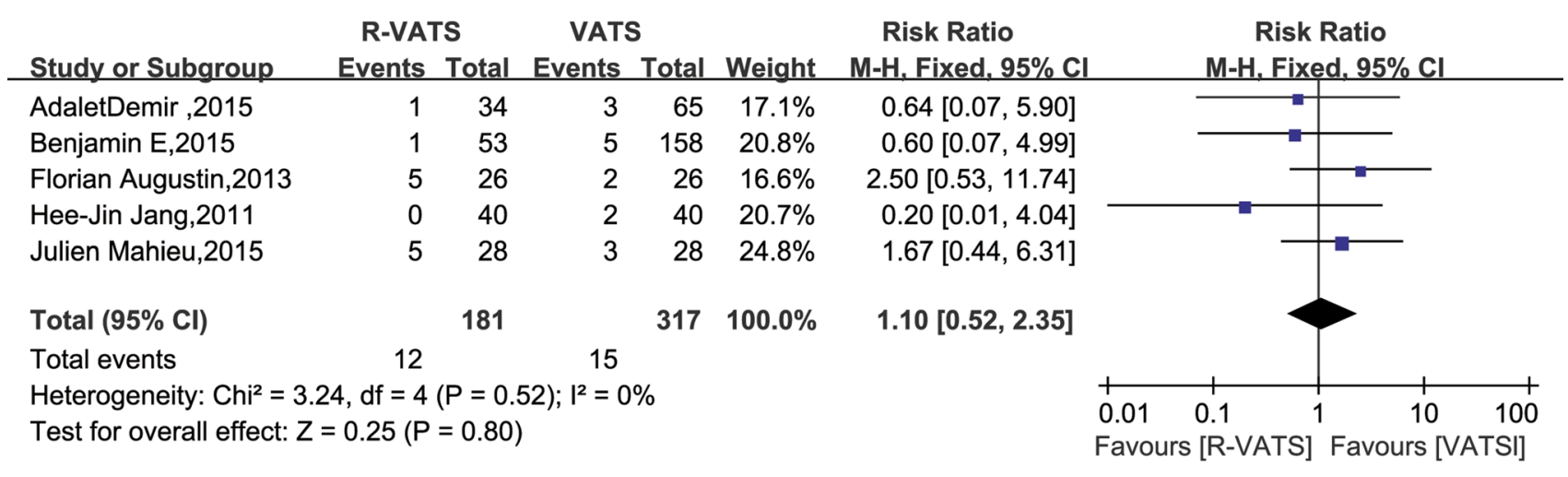

Figure 4: Forest plot presenting the number of dissected lymph nodes from the studies included. $95 \%$ CI: $95 \%$ confidence interval.

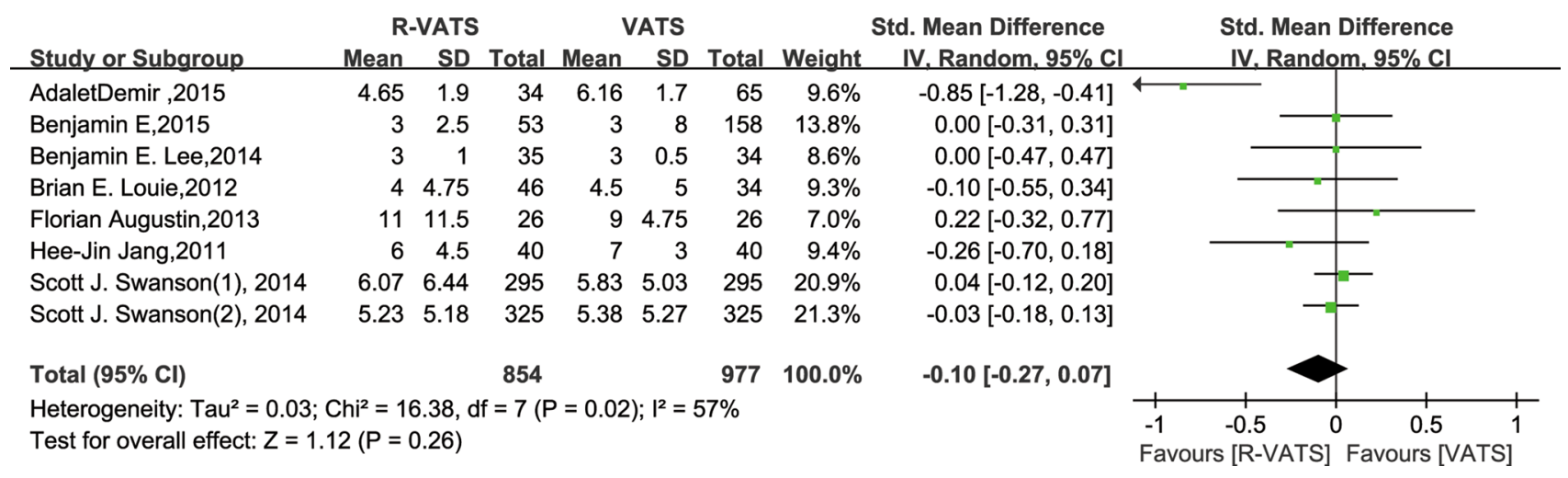

Figure 5: Forest plot presenting length of hospital stay from the studies included. $95 \%$ CI: $95 \%$ confidence interval.

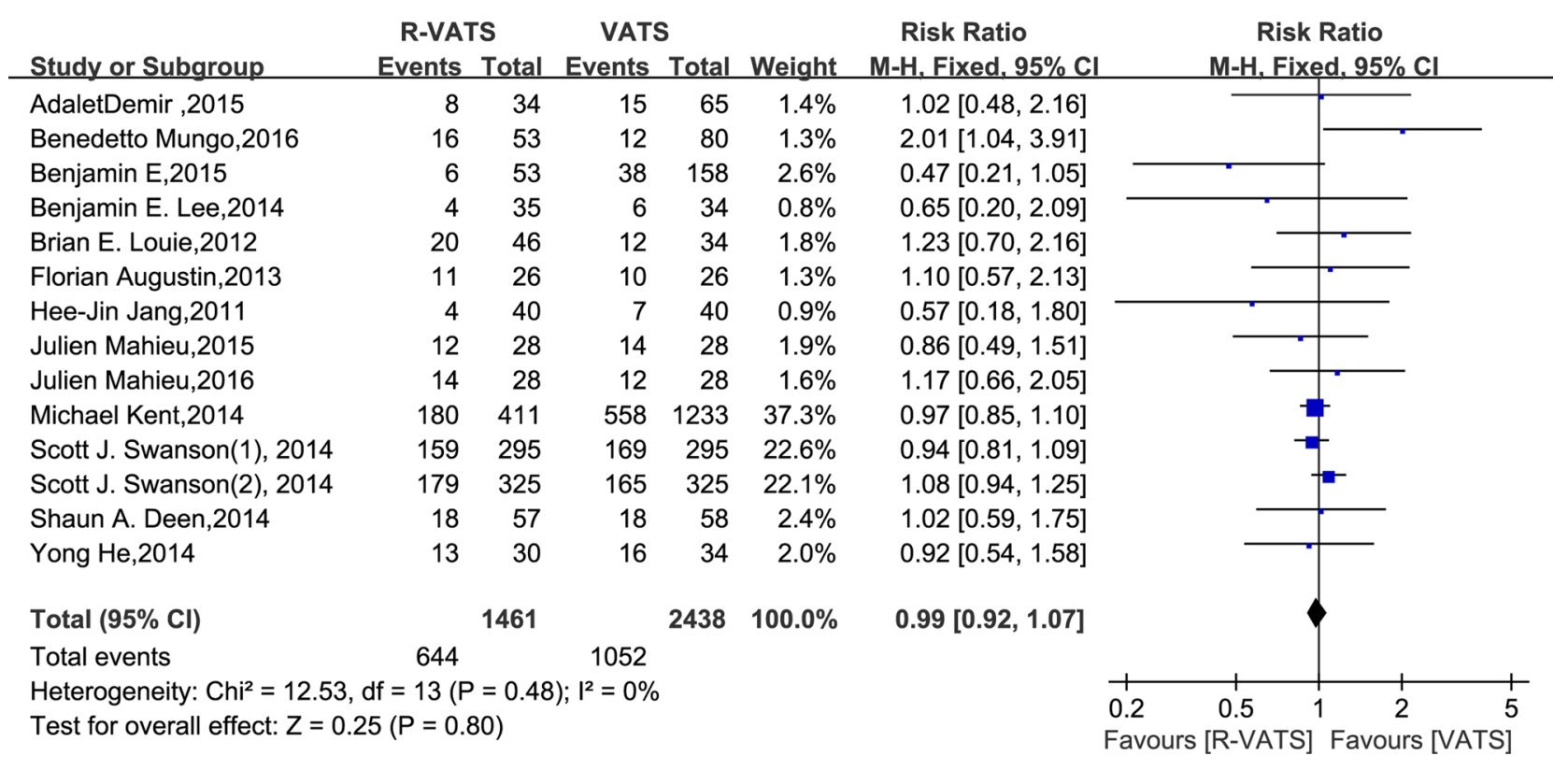

Figure 6: Forest plot presenting morbidity from the studies included. 95\% CI: 95\% confidence interval. 


\section{DISCUSSION}

Traditionally, randomized controlled trials (RCTs) has been used in meta-analysis. However, using nonrandomized controlled trials (NRCTs) might be a good method in meta-analysis of some clinical settings in which either the number or sample size of the RCTs is insufficient $[24,25]$.

In this meta-analysis, we found that there was a significant difference in operating time between R-VATS and VATS. Only one study of Yong He suggested that R-VATS was associated with a shorter time for operating time, compared with VATS approach. Whereas others suggested that operating time was shorter for VATS approach. This may be attributable to the additional set-up time required for R-VATS [26]. With increasing experience and set-up time gradually decreased, the actual time may be shorter in R-VATS. The technical advantage of R-VATS in the thoracic cavity will be more evident compared to the common VATS in the future. Although R-VATS offers a number of advantages over VATS, the results of our meta-analysis suggest that there are no additional clinical benefits for R-VATS over VATS. There were no significant differences in conversion, the number of lymph-node dissection, length of hospital stay, morbidity and mortality between R-VATS and VATS. From the point of clinical practice and patients, these parameters should be taken into account when deciding whether R-VATS technique is superior to the VATS technique.

Whether the R-VATS or VATS approach brings in more advantages remains a matter of debate.

Some studies have suggested that R-VATS was associated with a higher rate of intraoperative conversion, compared with VATS approach. Whereas others have suggested that conversion is comparable between the two approaches. In our analysis study, there was no difference in conversion rate between the R-VATS and VATS approaches. We observed that conversion rate was comparable in the two approaches. This is likely the result of more exquisite skills of surgeons and complete exposure of operation field. Owing to the advantages of three-dimensional optics, the stable camera platform and the flexible instrumentation, one potential strength of the robotic approach might be the thoroughness of the lymphadenectomy. Studies have suggested the robotic approach resulted in more samples of lymph nodes than the VATS approach. However, there was no difference in numbers of lymph nodes sampled between the R-VATS and VATS approaches in the current study. This is likely attributable to the operation subject scale differences and different pathological types for lung cancer from other studies.

Lobectomy is the main procedure type in these studies. Segmentectomy is included in studies of Deen SA and Demir A, while wedge resection is exsit in the study of Swanson SJ. Surgical resection maintains an important role in the treatment of lung carcinoma, so efforts must be directed towards determining methods to reduce morbidity and mortality to achieve optimal pulmonary dynamics in the perioperative periods, which will make a difference in the matter of length of hospital stay. Pulmonary morbidity is a major cause of mortality in patients with lung cancer. Previous series have reported that most of deaths to be directly related to peri-operative morbidity, in particular respiratory failure and pneumonia. In this metaanalysis, there were no significant differences between two groups for morbidity, leading to a similar result for the comparisons of overall mortality rate between two groups. The main direct causes of peri-operative mortality include hemorrhage, respiratory failure, pneumonia and myocardial event. Cardiac and infections are the main sources for morbidity, while the prolonged air leak and bronchopleural fistula also exsit for some cases.

Lung cancer is the leading cause of cancer death. Lung surgery has evolved in the past decades for the purpose of diagnosis or treatment. There are several different minimally invasive modalities accepted for lung

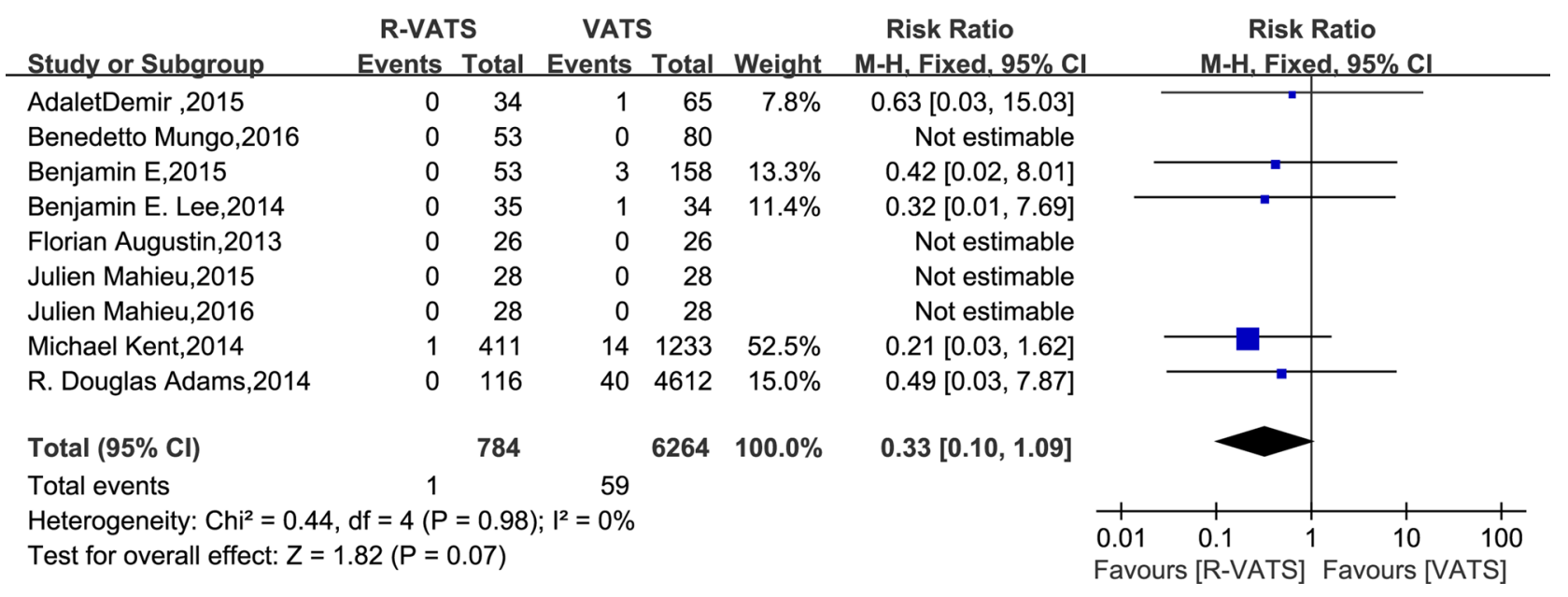

Figure 7: Forest plot presenting in-hospital mortality from the studies included. 95\% CI: 95\% confidence interval. 
cancer, such as robotic thoracic surgery(RTS) and videoassisted thoracic surgery(VATS) [17, 19]. Before the introduction of video-assisted thoracic surgery (VATS), lobectomy for lung cancer required thoracotomy and rib spreading [15, 27-29]. VATS is a much less traumatic approach than thoracotomy, resulting in less pain, shorter hospital stay and other advantages [30-33]. In 2000, the United States FDA approved the Da Vinci surgical robot system for clinical application. Application of the robotic surgical system has opened up a new era, with minimally invasive surgery now elevated to a new stage. The robotic surgery system has been widely used in urinary tract, hepatobiliary, cardiovascular and gynecological surgery [34-37]. Robot-assisted surgery is also being adopted in thoracic oncology and several types of mediastinal and lung resection [6, 38-41].

Owing to its limitations, only $15 \%$ to $30 \%$ of all thoracic operations were performed by VATS [42]. Since the introduction of the robotic system, a very wide range of attention has been paid to its use across the world. Despite the extensive experience in various fields of surgery, there is little evidence of superiority of R-VATS over VATS. Well-designed and adequately powered, blinded, randomized controlled trials are scarce and the risk for publication bias is significant $[43,44]$. The results of our meta-analysis are consistent with the previous studies $[15,16,18]$, which indicated that the robotic approach had comparable perioperative outcomes, but did not increase clinical benefits for patients.

However, the results of our meta-analysis should be interpreted with caution because of several limitations. First, data came from NRCTs, which might weaken the quality of the results. Second, reports in languages other than English were excluded, leading to potential bias. Third, types of lung cancer resection were not elaborated in studies included, the number of harvested number of lymph nodes may not be a reliable data in the circumstance of VATS technique. The accuracy in numbers of lymph nodes sampled for robotic resection appears to be more approximate to thoracotomy data when analyzed by clinical T stage [45]. Finally, patients' baseline characteristics differed between studies, and there was inevitably some variability in the surgical techniques and skills of surgeons. All surgeons need a period of time for the learning curve phase for a technique. Only in recent years, robotic technique has been increasingly used. Nevertheless, since there are no clear standards on the surgical procedures for robotic procedures, it would likely be difficult to set up a universal standard for surgeons according to the learning curve phase. Also the favored surgical approach varies dramatically among surgeons, leading to potential bias [46].

The results of this meta-analysis showed that VATS was associated with a shorter operative time. Thus, we suggest that R-VATS is an alternative to VATS for lung cancer resection without no prominent advantages. Further studies are required to confirm these results.

\section{MATERIALS AND METHODS}

\section{Search strategy}

The Pubmed, the Cochrane Library, and the Web of Science were searched systematically for all articles published in English until June 2016 to compare perioperative outcomes of R-VATS and VATS for lung cancer. The terms used for search were:"robotic" and "lung cancer". Two authors screened results of the literature search, and the reference lists of the included articles were also screened for potential studies. Two authors independently applied the inclusion and exclusion criteria, and any disagreement was resolved by a third reviewer.

\section{Inclusion and exclusion criteria}

For inclusion in the meta-analysis, a study had to fulfill the following criterion: (1) patients with lung cancer diagnosed; (2) compare the outcomes of R-VATS and VATS, regardless of other diseases; (3) report on at least one of the outcome measures mentioned below; and (4) the one of higher quality was included in the analysis if dual (or multiple) studies were reported by the same institution and/or authors.

Abstracts, letters, editorials and expert opinions, reviews without original data, case reports, and studies lacking outcome measures were excluded. The studies or data were also excluded when: 1) it was impossible to extract the appropriate data from the published results; 2) there was overlap between authors or centers; 3 ) the outcomes and parameters of patients were not clearly reported; (4) studies lacking information on outcomes.

\section{Outcomes of interest and data extraction}

Data abstraction and quality assessment were performed as described previously [47]. Briefly, two reviewers independently extracted the following parameters from each study: 1) first author and year of publication; 2) study population characteristics; 3 ) number of subjects who underwent each technique; and lastly, 4) intra-operative data, post-operative data, and pathologic details. The following outcomes were used to compare R-VATS and VATS techniques: 1) intra-operative data, which included operating time ( $\mathrm{min}$ ), and conversion; 2) post-operative data, which included hospital stay following surgery (days), morbility and mortality; and 3 ) pathologic details, which was number of lymph nodes harvested.

In this meta-analysis, patients were matched for operation time, conversion, lymph nodes harvested, length of hospital stay, morbidity and mortality in two groups. Operative time was defined as the time between the initial incision and complete wound closure, and for robotic surgeries it also included time of docking and 
undocking. Conversion was defined as the need to use a rib-spreading thoracotomy or the need to switch from robotic to conventional VATS. The number of lymphnode dissection was defined as the quantity of lymph-node harvested during surgeries. Length of hospital stay was defined as postoperative days. Morbidity was defined as any postoperative complications. Mortality was defined as any death occurring during initial hospitalization or within 30 days after surgery.

The quality of observational studies was assessed using the Newcastle-Ottawa scale. The Newcastle-Ottawa scale assesses the quality of study based on the following three aspects: (i) the selection of the study cohort (or cases/controls), (ii) the comparability of the cohorts (or cases/controls) and (iii) the outcome assessment for a cohort study, or the determination of the exposure for a case-control study. The quality of randomized trials was assessed using the Jadad scale [48]. The Jadad scale assesses the quality of randomized studies based on the following aspects: randomization, double blinding, withdrawals and dropouts. A score $\geq 3$ denotes a highquality study. The meta-analysis was performed according to the PRISMAguidelines [49].

\section{Statistical analysis}

The statistical analysis was conducted as described previously [47]. The mean and the variance for articles reporting the median, range and the size of the trial were deduced in a way as described in Stela Pudar Hozo,s article [50]. Briefly, Review Manager 5.2 (RevMan 5.2 ${ }^{\circledR}$, Nordic Cochrane Center and Copenhagen, Denmark) was used to perform the meta-analysis. The $I^{2}$ statistic was used to quantify the statistical heterogeneity of the studies included, and $I^{2}$ values of $25-49,50-74$ and $\geq 75 \%$ indicate low, moderate and high heterogeneity, respectively. When the $I^{2}$ value was $>50 \%$, indicating the presence of variability among the studies, we chose a random-effects models to perform the meta-analysis.

We analyzed dichotomous variables using estimation of risk ratios with a $95 \%$ confidence interval (95\% CI) and continuous variables using standardized mean difference (SMD) with a 95\% CI. Forest plots were used to present the results of the meta-analysis. A $P$-value $<0.05$ was considered to be significant.

\section{Authors' contributions}

ZPY,QX and LM participated in all aspects of the experiment and drafted the article. ZPY, LG and $\mathrm{XC}$ participated in the assays and the design of the study, YZP, LG, XC and CYN performed the statistical analysis. ZPY, WZL,WDL and LM conceived of the study, and participated in its design and helped to draft the manuscript. All authors read and approved the final manuscript.

\section{CONFLICTS OF INTEREST}

interests

The authors declare that they have no competing

\section{FUNDING}

This study was supported by grants from National Natural Science Foundation of China (81670350).

\section{REFERENCES}

1. McKenna RJ Jr, Houck W, Fuller CB. Video-assisted thoracic surgery lobectomy: experience with 1,100 cases. The Annals of thoracic surgery. 2006; 81:421-425; discussion 425-426.

2. Nagahiro I, Andou A, Aoe M, Sano Y, Date H, Shimizu N. Pulmonary function, postoperative pain, and serum cytokine level after lobectomy: a comparison of VATS and conventional procedure. The Annals of thoracic surgery. 2001; 72:362-365.

3. Ng CS, Lee TW, Wan S, Wan IY, Sihoe AD, Arifi AA, Yim AP. Thoracotomy is associated with significantly more profound suppression in lymphocytes and natural killer cells than video-assisted thoracic surgery following major lung resections for cancer. Journal of investigative surgery. 2005; 18:81-88.

4. Landreneau RJ, Mack MJ, Hazelrigg SR, Dowling RD, Acuff TE, Magee MJ, Ferson PF. Video-assisted thoracic surgery: basic technical concepts and intercostal approach strategies. The Annals of thoracic surgery. 1992; 54:800-807.

5. Melfi FM, Mussi A. Robotically assisted lobectomy: learning curve and complications. Thoracic surgery clinics. 2008; 18:289-295, vi-vii.

6. Augustin F, Bodner J, Wykypiel H, Schwinghammer C, Schmid T. Initial experience with robotic lung lobectomy: report of two different approaches. Surgical endoscopy. 2011; 25:108-113.

7. Melfi FM, Menconi GF, Mariani AM, Angeletti CA. Early experience with robotic technology for thoracoscopic surgery. European journal of cardio-thoracic surgery. 2002; 21:864-868.

8. Ma Y, Zhang P, Wang F, Yang J, Liu Z, Qin H. Association between vitamin $\mathrm{D}$ and risk of colorectal cancer: a systematic review of prospective studies. Journal of clinical oncology. 2011; 29:3775-3782.

9. Adams RD, Bolton WD, Stephenson JE, Henry G, Robbins ET, Sommers E. Initial multicenter community robotic lobectomy experience: comparisons to a national database. The Annals of thoracic surgery. 2014; 97: 1893-1898; discussion 1899-1900.

10. He Y, Coonar A, Gelvez-Zapata S, Sastry P, Page A. Evaluation of a robot-assisted video-assisted thoracoscopic surgery programme. Experimental and therapeutic medicine. 2014; 7:873-876. 
11. Mahieu J, Rinieri P, Bubenheim M, Calenda E, Melki J, Peillon C, Baste JM. Robot-Assisted Thoracoscopic Surgery versus Video-Assisted Thoracoscopic Surgery for Lung Lobectomy: Can a Robotic Approach Improve ShortTerm Outcomes and Operative Safety? The Thoracic and cardiovascular surgeon. 2015.

12. Lee BE, Shapiro M, Rutledge JR, Korst RJ. Nodal Upstaging in Robotic and Video Assisted Thoracic Surgery Lobectomy for Clinical N0 Lung Cancer. The Annals of thoracic surgery. 2015; 100:229-233; discussion 233-224.

13. Lee HS, Jang HJ. Thoracoscopic mediastinal lymph node dissection for lung cancer. Seminars in thoracic and cardiovascular surgery. 2012; 24:131-141.

14. Kent $M$, Wang $T$, Whyte $R$, Curran $T$, Flores $R$, Gangadharan S. Open, video-assisted thoracic surgery, and robotic lobectomy: review of a national database. The Annals of thoracic surgery. 2014; 97:236-242; discussion 242-234.

15. Augustin F, Bodner J, Maier H, Schwinghammer C, Pichler B, Lucciarini P, Pratschke J, Schmid T. Robotic-assisted minimally invasive vs. thoracoscopic lung lobectomy: comparison of perioperative results in a learning curve setting. Langenbeck's archives of surgery. 2013; 398:895-901.

16. Louie BE, Farivar AS, Aye RW, Vallieres E. Early experience with robotic lung resection results in similar operative outcomes and morbidity when compared with matched video-assisted thoracoscopic surgery cases. The Annals of thoracic surgery. 2012; 93:1598-1604; discussion 1604-1595.

17. Swanson SJ, Miller DL, McKenna RJ Jr, Howington J, Marshall MB, Yoo AC, Moore M, Gunnarsson CL, Meyers BF. Comparing robot-assisted thoracic surgical lobectomy with conventional video-assisted thoracic surgical lobectomy and wedge resection: results from a multihospital database (Premier). The Journal of thoracic and cardiovascular surgery. 2014; 147:929-937.

18. Jang HJ, Lee HS, Park SY, Zo JI. Comparison of the early robot-assisted lobectomy experience to videoassisted thoracic surgery lobectomy for lung cancer: a single-institution case series matching study. Innovations (Philadelphia, Pa). 2011; 6:305-310.

19. Deen SA, Wilson JL, Wilshire CL, Vallieres E, Farivar AS, Aye RW, Ely RE, Louie BE. Defining the cost of care for lobectomy and segmentectomy: a comparison of open, video-assisted thoracoscopic, and robotic approaches. The Annals of thoracic surgery. 2014; 97:1000-1007.

20. Demir A, Ayalp K, Ozkan B, Kaba E, Toker A. Robotic and video-assisted thoracic surgery lung segmentectomy for malignant and benign lesions. Interactive cardiovascular and thoracic surgery. 2015; 20:304-309.

21. Lee BE, Korst RJ, Kletsman E, Rutledge JR. Transitioning from video-assisted thoracic surgical lobectomy to robotics for lung cancer: are there outcomes advantages? The Journal of thoracic and cardiovascular surgery. 2014; 147:724-729.
22. Mahieu J, Rinieri P, Bubenheim M, Calenda E, Melki J, Peillon C, Baste JM. Robot-Assisted Thoracoscopic Surgery versus Video-Assisted Thoracoscopic Surgery for Lung Lobectomy: Can a Robotic Approach Improve ShortTerm Outcomes and Operative Safety? The Thoracic and cardiovascular surgeon. 2016; 64:354-362.

23. Mungo B, Hooker CM, Ho JS, Yang SC, Battafarano RJ, Brock MV, Molena D. Robotic Versus Thoracoscopic Resection for Lung Cancer: Early Results of a New Robotic Program. Journal of laparoendoscopic \& advanced surgical techniques Part A. 2016; 26:243-248.

24. Mathurin P, Raynard B, Dharancy S, Kirzin S, Fallik D, Pruvot FR, Roumilhac D, Canva V, Paris JC, Chaput JC, Naveau S. Meta-analysis: evaluation of adjuvant therapy after curative liver resection for hepatocellular carcinoma. Alimentary pharmacology \& therapeutics. 2003; 17: 1247-1261.

25. Zhou Y, Zhao Y, Li B, Xu D, Yin Z, Xie F, Yang J. Metaanalysis of radiofrequency ablation versus hepatic resection for small hepatocellular carcinoma. BMC gastroenterology. $2010 ; 10: 78$.

26. Ng SS, Lee JF, Yiu RY, Li JC, Hon SS. Teleroboticassisted laparoscopic abdominoperineal resection for low rectal cancer: report of the first case in Hong Kong and China with an updated literature review. World journal of gastroenterology. 2007; 13:2514-2518.

27. Swanson SJ, Herndon JE 2nd, D'Amico TA, Demmy TL, McKenna RJ Jr, Green MR, Sugarbaker DJ. Video-assisted thoracic surgery lobectomy: report of CALGB 39802 - a prospective, multi-institution feasibility study. Journal of clinical oncology. 2007; 25:4993-4997.

28. Whitson BA, D'Cunha J, Andrade RS, Kelly RF, Groth SS, Wu B, Miller JS, Kratzke RA, Maddaus MA. Thoracoscopic versus thoracotomy approaches to lobectomy: differential impairment of cellular immunity. The Annals of thoracic surgery. 2008; 86:1735-1744.

29. Paul S, Altorki NK, Sheng S, Lee PC, Harpole DH, Onaitis MW, Stiles BM, Port JL, D'Amico TA. Thoracoscopic lobectomy is associated with lower morbidity than open lobectomy: a propensity-matched analysis from the STS database. The Journal of thoracic and cardiovascular surgery. 2010; 139:366-378.

30. Farjah F, Wood DE, Mulligan MS, Krishnadasan B, Heagerty PJ, Symons RG, Flum DR. Safety and efficacy of video-assisted versus conventional lung resection for lung cancer. The Journal of thoracic and cardiovascular surgery. 2009; 137:1415-1421.

31. Cheng D, Downey RJ, Kernstine K, Stanbridge R, Shennib H, Wolf R, Ohtsuka T, Schmid R, Waller D, Fernando H, Yim A, Martin J. Video-assisted thoracic surgery in lung cancer resection: a meta-analysis and systematic review of controlled trials. Innovations (Philadelphia, Pa). 2007; 2:261-292.

32. Grogan EL, Jones DR. VATS lobectomy is better than open thoracotomy: what is the evidence for short-term outcomes? Thoracic surgery clinics. 2008; 18:249-258. 
33. Rueth NM, Andrade RS. Is VATS lobectomy better: perioperatively, biologically and oncologically? The Annals of thoracic surgery. 2010; 89:S2107-2111.

34. Lanfranco AR, Castellanos AE, Desai JP, Meyers WC. Robotic surgery: a current perspective. Annals of surgery. 2004; 239:14-21.

35. Kaushik D, High R, Clark CJ, LaGrange CA. Malfunction of the Da Vinci robotic system during robot-assisted laparoscopic prostatectomy: an international survey. Journal of endourology. 2010; 24:571-575.

36. Oleynikov D. Robotic surgery. The Surgical clinics of North America. 2008; 88:1121-1130, viii.

37. Patriti A, Ceccarelli G, Ceribelli C, Bartoli A, Spaziani A, Cisano C, Cigliano S, Casciola L. Robot-assisted laparoscopic management of cardia carcinoma according to Siewert recommendations. The international journal of medical robotics + computer assisted surgery. 2011; 7:170-177.

38. Giulianotti PC, Coratti A, Angelini M, Sbrana F, Cecconi S, Balestracci T, Caravaglios G. Robotics in general surgery: personal experience in a large community hospital. Archives of surgery (Chicago, Ill : 1960). 2003; 138:777-784.

39. Park BJ, Flores RM, Rusch VW. Robotic assistance for video-assisted thoracic surgical lobectomy: technique and initial results. The Journal of thoracic and cardiovascular surgery. 2006; 131:54-59.

40. Gharagozloo F, Margolis M, Tempesta B, Strother E, Najam F. Robot-assisted lobectomy for early-stage lung cancer: report of 100 consecutive cases. The Annals of thoracic surgery. 2009; 88:380-384.

41. Veronesi G, Galetta D, Maisonneuve P, Melfi F, Schmid RA, Borri A, Vannucci F, Spaggiari L. Four-arm robotic lobectomy for the treatment of early-stage lung cancer. The Journal of thoracic and cardiovascular surgery. 2010; 140:19-25.

42. Hanna JM, Berry MF, D'Amico TA. Contraindications of video-assisted thoracoscopic surgical lobectomy and determinants of conversion to open. Journal of thoracic disease. 2013; 5:S182-189.
43. Barbash GI, Glied SA. New technology and health care costs - the case of robot-assisted surgery. The New England journal of medicine. 2010; 363:701-704.

44. Delaney CP, Senagore AJ, Ponsky L. Robot-assisted surgery and health care costs. The New England journal of medicine. 2010; 363:2175; author reply 2176.

45. Wilson JL, Louie BE, Cerfolio RJ, Park BJ, Vallieres E, Aye RW, Abdel-Razek A, Bryant A, Farivar AS. The prevalence of nodal upstaging during robotic lung resection in early stage non-small cell lung cancer. The Annals of thoracic surgery. 2014; 97:1901-1906; discussion 1906-1907.

46. Yang HX, Woo KM, Sima CS, Bains MS, Adusumilli PS, Huang J, Finley DJ, Rizk NP, Rusch VW, Jones DR, Park BJ. Long-term Survival Based on the Surgical Approach to Lobectomy For Clinical Stage I Nonsmall Cell Lung Cancer: Comparison of Robotic, Video-assisted Thoracic Surgery, and Thoracotomy Lobectomy. Annals of surgery. 2016.

47. Deo SV, Dunlay SM, Shah IK, Altarabsheh SE, Erwin PJ, Boilson BA, Park SJ, Joyce LD. Dual anti-platelet therapy after coronary artery bypass grafting: is there any benefit? A systematic review and meta-analysis. Journal of cardiac surgery. 2013; 28:109-116.

48. Jadad AR, Moore RA, Carroll D, Jenkinson C, Reynolds DJ, Gavaghan DJ, McQuay HJ. Assessing the quality of reports of randomized clinical trials: is blinding necessary? Controlled clinical trials. 1996; 17:1-12.

49. Moher D, Liberati A, Tetzlaff J, Altman DG. Preferred reporting items for systematic reviews and meta-analyses: the PRISMA statement. PLoS medicine. 2009; 6:e1000097.

50. Hozo SP, Djulbegovic B, Hozo I. Estimating the mean and variance from the median, range, and the size of a sample. BMC medical research methodology. 2005; 5:13. 